to be satisfactorily explained, but the fact of its failure, coupled with the mechanical troubles which were experienced with it, give powerful backing to the arguments which have already been advanced against it. A closed apparatus was brought back from Everest, and was tested again under actual climbing conditions to ascertain whether there had been any mechanical fault which might have caused the failure. Some repairs were necessary, but the canister was not exchanged, and neither the breathing valve on the flexible reservoir nor the mica valves on the face-piece were touched. The test showed that at these low altitudes (up to 2,000 ft.) the apparatus worked perfectly well.

Perhaps the hardest thing of all is to estimate the advantage conferred by the use of oxygen. Comparison of climbing speeds is difficult and dangerous, but from the trials of 1938 , it would seem that from $23,000 \mathrm{ft}$. to $26,000 \mathrm{ft}$., the use of oxygen in the open apparatus at 2 litres a minute has only a slight effect on natural climbing speed. The reduction of strain and fatigue, however, provides ample justification for its use at this height. Above 26,000 ft., the increase in climbing speed becomes more and more apparent. The maximum advantage is obtained, as one might expect, on easy ground where the climber moves with steady rhythm. More difficult climbing requiring greater exertion results in an increase in the rate of breathing, and with the open apparatus this implies a fall in the partial pressure of oxygen entering the lungs.

We suffered in 1938 from the necessity of taking two different forms of apparatus each with different sized cylinders, but it is hoped that the results we obtained will enable a future expedition to make a definite choice.

\footnotetext{
${ }^{1}$ See Prof. G. I. Finch's account in "The Assault on Mount Everest", p. 264 ; also P. J. H. Unna, "The Oxygen Equipment of the p. 264 ; also P. J. H. Unna, "The Oxygen B

2 See "The Medical and Physiological aspects of the Mount Fverest Expeditions", by C. B. Warren, Geog. J., 90 (August 1937).
}

\title{
A Hundred Years of Photography
}

$\mathrm{T}$ HE satisfactory recording of a scene by photographic means first became possible in 1839, when Daguerre published details of the process which bears his name. The 'base' consisted of a silver or silvered metal plate iodized on the surface, and the exposure amounted to about ten minutes in bright sunlight. 'Development' took place in mercury vapour, which acted preferentially upon the exposed portions, yielding a direct positive. A serious disadvantage of the process was the fact that only one picture was obtained, and there was no known process of copying originals. Fox-Talbot in 1840 carried the art a stage further by obtaining negatives on paper, using silver iodide as sensitive material, developing in gallic acid, waxing the paper to make it transparent and making prints by exposing in front of a piece of paper sensitized with silver chloride.

The chief drawback at this time was the length of exposure necessary. Scott-Archer in 1851 considerably increased the speed with his wet collodion process. This latter process was the first successful attempt to use a protective colloid for suspending the light-sensitive substance. The wet collodion process was very successful and its chief drawback was the fact that the plate had to be exposed while still wet, thus necessitating the preparation of the plate 'in the field' immediately before exposure.

The next important step was taken in 1871, when Maddox used gelatine instead of collodion as protective colloid and produced the first dry plate. The dry plate was not successful until later, when it was found essential to remove the salts formed by the reaction between silver nitrate and soluble halide. In addition to a gain in speed, the dry plate had an enormous advantage over the wet plate for field work, but the wet plate is still extensively used to-day in the photo-engraving industry.

The spectral sensitivity of the silver halides is confined to the blue and violet end of the visible spectrum, but it was discovered in 1873 that the addition of certain dyes conferred added sensitivity in the direction of increasing wave-length. Since then a systematic search has been made, and is still going on, for other sensitizing dyes giving greater sensitivity and extending the spectral range of the added sensitivity. It is possible to-day to sensitize to all wave-lengths up to about $11,000 \mathrm{~A}$.

Since the discovery of the dry plate, no fundamental changes have taken place in photography. All the advance has been towards improved photographic quality (for example, latitude and gradation, speed, graininess and spectral sensitivity). The inherent sensitivity of the silver halides to ultra-violet, $\mathrm{X}$-rays and $\gamma$-rays has found its application in scientific work. Indeed, during the last fifty years, photography has been an invaluable tool in scientific research. One has only to recall the part played by photography in 
astronomy and spectroscopy to realize how difficult, and in some cases almost impossible, much of the work would have been without it. On the other hand, the manufacture of photographic emulsions is still largely governed by trial and error, though of course a great deal of knowledge has been gained empirically. The gelatine used is a natural product which contains compounds essential to the production of a satisfactory emulsion, and although something is known of the nature of these compounds their significance is not yet fully understood. Photography has gained much from the advance in organic chemistry, which has paved the way towards the synthesis of sensitizing dyes. Enormous numbers of dyes have been prepared and tested for the sake of a small percentage which have proved useful. The mechanism of dye sensitization is not yet understood, but by a systematic study of the behaviour of dyes sufficient empirical knowledge has been obtained at least to guide the search for new dyes into more fruitful channels.

It is a far cry from the Daguerreotype plate of 1839 requiring 10 minutes' exposure in sunlight to the plate or film of 1939 requiring 0.01 second under similar conditions of lighting and lens aperture, and it appears to-day that the speed cannot be greatly increased while retaining other factors such as grain within reasonable limits. The same could, however, have been said five years ago, yet the speed of the fastest available material has been increased several times since then.

Even a brief review such as this would be incomplete without a word on colour photography. A practical method of additive colour reproduction was conceived so early as 1868 , but could not be developed into a practical process until satisfactory panchromatization was achieved. The mosaic screen processes of to-day are the outcome of these early theories and have reached their present stage of perfection largely by the increase in speed and colour-sensitivity of photographic materials in general. Subtractive colour processes have within the last few years received added impetus by the development of colour former and developer coupling methods, as well as improvements in emulsion-making technique. Most of the practical advance in colour photography has taken place during the last thirty years, mainly because improvement was not possible in any colour process until efficient sensitization in the red region of the spectrum had been achieved.

The pioneers of photography were concerned with discovering a process by which the beautiful little pictures shown on the screen of the camera obscura could be permanently recorded, but the art has proved of such important application in the field of scientific research that we may well pause to commemorate the centenary of photography.

The Royal Photographic Society held a series of special centenary lectures during last winter session; celebrations were held in Paris earlier this year, and on May 17 a joint meeting of the Royal Society of Arts and the Royal Photographic Society was held in the lecture hall of the Royal Society of Arts, London. This joint meeting was particularly appropriate, because it was out of the Royal Society of Arts that the Royal Photographic Society, the first photographic society in the world, was formed in 1853. Dr. Olaf Bloch opened the proceedings from the chair and the first speaker was Mr. Peter le Neve Foster, the great-grandson of Peter le Neve Foster who, as a member of the Royal Society of Arts, was partly instrumental in the formation of the Royal Photographic Society. The speaker referred to papers on photographic subjects read before the Society between 1840 and the formation of the Royal Photographic Society.

The next speaker, Miss M. T. Talbot, gave a very interesting sidelight on the character and family life of her grandfather William Henry FoxTalbot, who may be called the pioneer of photography in Great Britain. He was the originator of the negative-positive process, whereby any number of copies could be obtained from one original.

Mr. Dudley Johnston then spoke on behalf of the Royal Photographic Society and stressed the cordial relations that had always existed between that body and the Royal Society of Arts. He gave an outline of the history of the formation of the Royal Photographic Society, which arose out of the exhibition of photographs held in 1852 under the auspices of the Royal Society of Arts. He read extracts from correspondence between the early organizers who were responsible for the formation of the Royal Photographic Society, from which it appeared that Fox-Talbot generously relinquished his patent rights on the calotype process in favour of the amateur photographer in order to make the formation of a photographic society possible.

Mr. A. J. Bull then gave a demonstration of FoxTalbot's photogenic paper, and the wet-collodion process originated by Scott-Archer in 1851 and still extensively used in the photo-engraving industry.

A number of exhibits of historic interest were on view. Some early cameras of Fox-Talbot were supplied with a hole and cork in the front, so that the operator could remove the cork and apply his eye to see how the exposure was getting on. Of scientific interest was the result of an attempt by Sir William Crookes to photograph the moon in 1855. In addition, photographs made by the early processes, fine as some of them were, showed the enormous progress that has been made in the last hundred years. 